\title{
Nutrient Resource Requirements for Large-scale Microalgae Biofuel Production: Multi-
}

\section{pathway Evaluation}

\author{
Benjamin K. Shurtz ${ }^{\mathrm{a}}$, Byard Wood ${ }^{\mathrm{a}}$, \& Jason C. Quinn ${ }^{\mathrm{b}}$ * \\ ${ }^{a}$ Department of Mechanical and Aerospace Engineering, 4130 old Main Hill, Utah State University, Logan, UT, US, 84322 \\ ${ }^{b}$ Department of Mechanical Engineering, 1374 Campus Delivery, Colorado State University, Fort Collins, CO, 80523
}

*Corresponding author: 1374 Campus Delivery Fort Collin, CO, 970-581-7992 Email: Jason.Quinn@colostate.edu 


\section{Abstract}

Growing demand for energy worldwide has increased interest in the production of renewable fuels, with microalgae representing a promising third generation feedstock. This study presents the use of a modular engineering process model, informed through literature, to evaluate the nitrogen and phosphorus resource demand of five microalgae to biofuels production systems. The baseline scenario, representative of an economically viable large-scale production system, includes sub-process models for growth, dewater, lipid extraction, anaerobic digestion, and biofuel conversion. Baseline modeling results combined with current US resource availability from fertilizer and wastewater show nitrogen and phosphorus requirements represent a potential barrier to the large-scale development of microalgae based biofuels. Baseline results show municipal wastewater sources can provide sufficient nutrients to produce 3.8 billion gallons of fuel per year, corresponding to $6 \%$ of the DOE goal of 60 billion gallons per year. Results from modeling of alternative production scenarios shows hydrothermal liquefaction to be a promising technology in terms of resource consumption and the use of lipid extracted algae as a valueadded co-product is limited due to nutrient recovery requirements for scalability. Optimistic and conservative process scenarios are simulated to bound the total resource demand and represent practical best and worst case scenarios.

Keywords: biofuel; microalgae; model; nutrients; scalability

Abbreviations: $\mathrm{AD}$-anaerobic digestion, $\mathrm{BGY}$-billion gallons per year, $\mathrm{CO}_{2}$-carbon dioxide, $\mathrm{C}: \mathrm{N}$ : $\mathrm{P}$-carbon: nitrogen: phosphorus, DOE-Department of Energy, HTL-hydrothermal liquefaction, LCA-life cycle assessment, LEA-lipid-extracted algae, Mmt-million metric tons, TEA-techno-economic analysis, TGYtrillion gallons per year, TS-total solids, VS-volatile solids 


\section{Introduction}

Increasing volatility in energy availability and cost, as well as the environmental impacts of fossil fuel use, has resulted in the domestic production of renewable fuels. The US Department of Energy (DOE) has quantified the level of interest in, and need for, renewable fuel through the establishment of a goal for the year 2030 that $30 \%$ of US transportation fuel or 60 billion gallons per year (BGY) will be derived from renewable sources [1]. A variety of second and third generation terrestrial based feedstock options exist, but microalgae have several advantages, including higher solar energy conversion efficiency, the ability to be grown on non-arable land, utilize impaired waters, and integration with various low value nutrient (nitrogen and phosphorus) sources including wastewater and point source carbon dioxide $\left(\mathrm{CO}_{2}\right)[2,3]$. Furthermore, microalgae are of interest in wastewater treatment for the removal of nitrogen and phosphorus [4-6]. The many advantages make microalgae one of the more promising feedstocks for production of renewable biofuels.

Researchers have evaluated the requirements, implications, and barriers to microalgae biofuel production at the scale required for the DOE 2030 goal through techno-economic analysis (TEA), life cycle assessment (LCA), and resource assessment. The majority of the TEAs and LCAs to date have developed system models of large-scale production facilities in an effort to quantify the energy and mass requirements, with results limited to financial costs and environmental impact [7-24]. Results from TEAs have suggested that higher value co-products from the lipid extracted algae (LEA) could improve 
the economics of biofuel production. The impacts of selling a co-product on the nutrient requirements of the system have not been fully characterized $[14,18]$. Published LCAs contain results focused on energy use and carbon emissions, with minimal analysis regarding scale-up limitations based on nutrient requirements $[15,23,24]$. Resource assessments have evaluated in detail the impact and availability of land, water, and $\mathrm{CO}_{2}$ requirements on the scalability of microalgae based biofuels, with results showing land does not currently represent a resource limitation, while water and $\mathrm{CO}_{2}$ will be limiting resources in some regions of the US [25-32]. Pate et al. [33] performed a high-level, low-granularity evaluation of the water, land, $\mathrm{CO}_{2}$ and nutrient requirements for large-scale production based on a mass balance assessment. Model details include only microalgae cultivation and omit all other steps of the biofuel production system. Their results provide the order of magnitude to expect for resource demand, but are inadequate due to the limited model scope. Venteris et al. [32] perform an assessment which includes land, water, $\mathrm{CO}_{2}$ and nutrient requirements of various pathways that is constructed on a system model comprised of sub-process models. However, the sub-process models for harvest, extraction (lipid extraction or $\mathrm{HTL}$ ), and conversion to fuel is limited to individual efficiency factors. Additional nutrient assessments make claims that seawater and wastewater can potentially provide the nutrients necessary for large-scale microalgae production, but provide no justification for these claims [34, 35]. The feasibility of integrating wastewater with microalgae cultivation as a source of water and nutrients for microalgae growth, as well as effective wastewater treatment has been established [2, 3, 36-38], but such studies have not extended results to evaluate the potential scalability at levels consistent with DOE renewable fuel goals. Despite the knowledge gained through previous TEAs, LCAs, and resource assessments, a need remains for thorough evaluation of the nutrient demand for large-scale biofuel production from microalgae.

Large-scale engineering system models are needed to quantify the nutrient requirements in the microalgae to biofuel process and evaluate the potential for various nutrient sources such as fertilizer 
and wastewater to meet the corresponding resource needs. This study assesses the large-scale resource requirements of multiple pathways of the microalgae to biofuel production processes. The work utilizes a modular engineering process model of the microalgae to biofuel production system to evaluate the nutrient requirements for baseline, optimistic, conservative, LEA co-product, and hydrothermal liquefaction (HTL) conversion process scenarios. The engineering system model, representative of a near-term large-scale system, includes growth, dewater, lipid extraction, anaerobic digestion (AD), and biofuel conversion processes for a system boundary that is consistent with the "well to pump" of LCA modeling. Optimistic and conservative scenarios were developed to encompass the variability of process efficiencies within the baseline system, account for advancements in processing technology, and provide bounds for the resource requirements. Alternative production processes were modeled which include a system based on the production of fuel with LEA co-products and the utilization of an alternative conversion and nutrient recycling process, HTL. Total nutrient requirements were determined for an annual fuel production level of 10 billion gallons. Discussion focuses on the results for resource requirements for the five production scenarios, system scalability within the US, a comparison of results to previous resource assessments, and sensitivity of resource results to model inputs to inform future research areas for decreasing nutrient requirements.

\section{Methods}

A modular engineering system model, designed to track mass flow, was developed in order to

2 quantify the resource requirements of a large-scale microalgae to biofuel production system while

3 incorporating the ability to evaluate alternative process technologies. Modeling work was performed at

4 a plant production level of 10 million gallons of gasoline equivalent per year $[39,40]$. The process

5 model, shown in Figure 1, includes 24 inputs used to characterize the production system with process

6 losses and efficiencies in each step included. Five production scenarios were modeled, with the 

supplementary material.
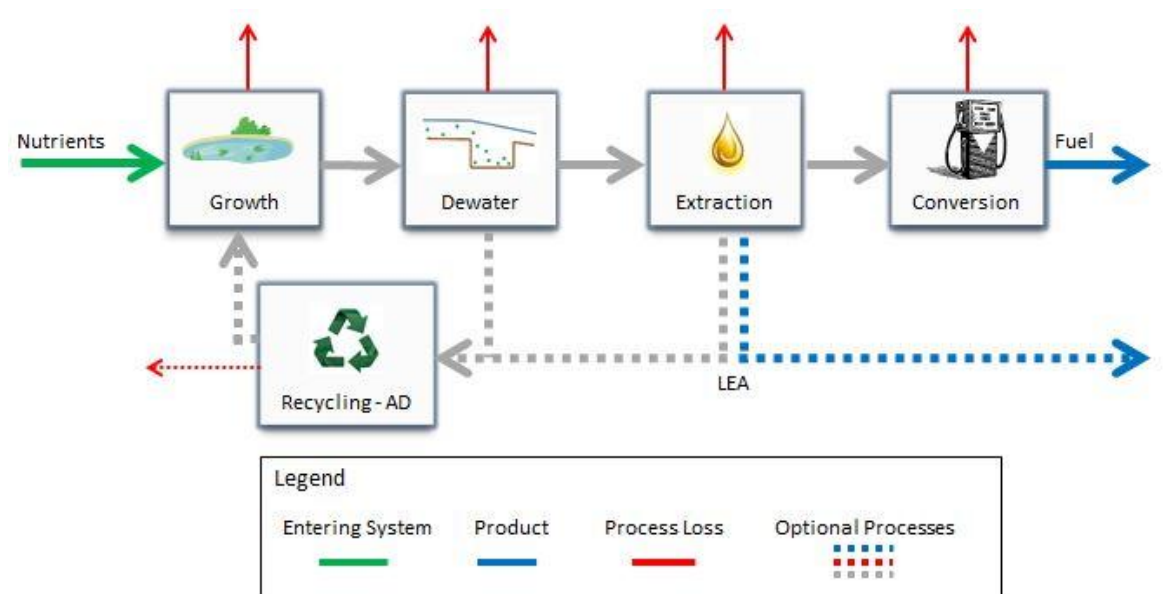

Figure 1. Engineering process model of the microalgae to biofuel production system used to model five production scenarios. Detailed system models for each scenario presented in supplementary material

\subsection{Baseline, Optimistic, and Conservative Scenarios}

The baseline scenario is intended to represent a near-term, large-scale microalgae to biofuel production system $[7,8,10,11,15,22,23,41-48]$. The baseline scenario is based on mature technologies and for example includes a lipid extraction system as this technology has been demonstrated at commercial scale for other oil based feedstocks [49-51]. The model includes growth, dewater, lipid extraction, biofuel conversion, and resource recycling through AD as the process steps $[14,15,22,52]$. In order to establish bounds on resource demand, optimistic and conservative scenarios are modeled. The optimistic scenario is comprised of the most efficient values reported in literature for each process, typically at bench or lab-scale, and represents the biofuel production system with the lowest nutrient demand. The optimistic scenario requires advancements in each of the processing technologies to be viable at large-scale. The conservative scenario represents technologies that have been demonstrated on a commercial scale, and results in the highest nutrient demand $[8,53,54]$. It is 
recognized that at commercial scale, processes will inherently have a loss to the environment or a waste

27 stream, so a loss is included in each process and standardized due to uncertainty. The baseline process model loss was assumed to be $1 \%$ and was cut in half for the optimistic case and doubled for the conservative case, corresponding to $0.5 \%$ and $2 \%$, respectively, with justification presented in each subprocess.

\subsubsection{Growth}

The production system modeled is assumed to produce microalgae that is rich in lipid from nitrogen induced stress at a rate of 13 grams ash free dry weight per square meter per day $\left(\mathrm{g} \mathrm{m}^{-2} \mathrm{~d}^{1}\right)$ $[52,55]$. A lipid percentage of $30 \%$ was selected for the baseline as a mid-range, realistic value to expect from a large-scale growth system, with $40 \%$ and $20 \%$ representing the optimistic and conservative cases, respectively $[14,15,27,33,52,54]$. The percent of lipids that are phospholipids was assumed to be $25 \%$ for the baseline, the average value reported by Chen et al. [56], and was taken as 5\% for the optimistic scenario and $30 \%$ for the conservative scenario $[15,56]$. The processing of biomass in a timely manner cultivation. The modeled system included a minimal process loss based on minimal delay in processing [57-59]. A biomass carbon content of $50 \%$ was assumed for the baseline and unchanged for the will impact the composition of the microalgae with the biorefinery assumed to be co-located with optimistic and conservative scenarios as it is a generally accepted value $[15,33,60,61]$. The hydrogen content of the microalgae was selected to be $7.5 \%, 6 \%$, and $9 \%$ for the baseline, optimistic, and conservative values, respectively [62]. The elemental composition of the microalgae is modeled through a molar carbon : nitrogen : phosphorus (C:N:P) ratio, which can vary depending on the state of growth $[55,63]$. The C:N:P ratio assumed for the baseline system is 106:16:1 based on the operation of a largescale photobioreactor production facility cultivating Nannochloropsis [64, 65]. The C:N:P ratio was assumed to be 166:20:1 for the optimistic case, as presented by Smith [66], which increases the C:N ratio by approximately $20 \%$ from the baseline. For the conservative case, $79: 16: 1$ was selected to 
provide an equal but opposite deviation from the baseline as the optimistic scenario. The range for the

51 microalgae composition is intended to capture the variability expected in various species and

52 requirements of alternative growth platforms.

Growth was modeled based on a batch cultivation system. Nitrogen absorption in the growth

54 phase is assumed to be $99 \%$ over the course of the batch, with the remainder being absorbed by competitive species or converted to di-nitrogen mono-oxide $[67,68]$. Nitrogen uptake in the optimistic and conservative scenarios was assumed to be $99.7 \%$ and $98 \%$, respectively $[67,69]$.

\section{$57 \quad$ 2.1.2 Dewatering}

Multiple possible dewatering processes exist for the baseline scenario. The selection of the

59 baseline technologies was driven by performance and large-scale viability. This study assumed

60 integration of dissolved air flotation [15, 70-72] with a $10 \%$ biomass loss followed by centrifugation [15,

6171,73 ] with a 5\% biomass loss, which were combined for an overall 14.5\% biomass loss going from 1\%

62 solids to $20 \%$ solids [15]. The lost biomass was assumed to be caught by a filter in the water recycling

63 process and sent to the AD. Filtration of the recycled water is required to ensure minimal contamination

64 in the growth system. The optimistic scenario considered only a centrifuge with a minimal biomass loss

65 of $2 \%$, and the conservative scenario assumed a $20 \%$ loss that would be expected from low-energy

66 harvesting technologies such as bio-flocculation [39].

\section{$67 \quad$ 2.1.3 Lipid Extraction and Conversion}

68 The lipid extraction process contains two fundamental avenues for lipid loss, first in lipids that

69 are unavailable to extraction and second in the incomplete recovery of the extracted lipid. For the

70 baseline, it is assumed $10 \%$ of the biomass passes through the system without lipid extraction. An

71 additional $5 \%$ of the available oil is assumed to be non-recoverable $[15,74]$. The unaffected biomass was

72 assumed to be sent to the AD. Both of the extraction parameters were varied by $\pm 50 \%$ of their baseline 
73 values for the optimistic and conservative scenarios, which corresponds to $5 \%$ and $15 \%$ for the biomass

74 passing through, and $2 \%$ and $8 \%$ for available but un-extracted oil [15]. For the conversion of extracted

75 lipid to biofuel, transesterification was modeled with $99 \%$ of the lipid entering the process converted to

76 biofuel $[52,75]$. The process loss modeled in this step is based on what is expected from a large-scale

77 production facility [15, 39, 52, 74-77].

\subsubsection{Recycling-Anaerobic Digestion}

The baseline recycling process utilizes an AD for nutrient recovery and biogas generation from the LEA and whole biomass recovered from the filtration of the centrate in the dewatering step [52]. The biogas production of the AD system was modeled based on the microalgae composition in terms of volatile solids (VS) and total solids (TS), methane yield per gram of volatile solids (g-VS), and percent methane $\left(\mathrm{CH}_{4}\right)$ content in the biogas. A characteristic of $0.94 \mathrm{~g}-\mathrm{VS} \mathrm{g-TS}{ }^{-1}$ for whole biomass, and $0.90 \mathrm{~g}$ VS g-TS ${ }^{-1}$ for LEA was assumed and kept constant for all scenarios $[75,78]$. The biogas yield from whole biomass was assumed to be $0.43 \mathrm{~L}-\mathrm{CH}_{4} \mathrm{~g}-\mathrm{VS}{ }^{-1}$ at $67 \% \mathrm{CH}_{4}, 0.80 \mathrm{~L}-\mathrm{CH}_{4} \mathrm{~g}-\mathrm{VS}{ }^{-1}$ at $62 \% \mathrm{CH}_{4}$, and $0.25 \mathrm{~L}-\mathrm{CH}_{4} \mathrm{~g}$ $\mathrm{VS}^{-1}$ at $72 \% \mathrm{CH}_{4}$ for the baseline, optimistic, and conservative scenarios, respectively [78-80]. Similarly for the digestion of LEA, biogas yield and composition for the baseline, optimistic, and conservative scenarios were assumed to be $0.22 \mathrm{~L}-\mathrm{CH}_{4} \mathrm{~g}-\mathrm{VS}^{-1}$ at $59 \% \mathrm{CH}_{4}, 0.31 \mathrm{~L}-\mathrm{CH}_{4} \mathrm{~g}-\mathrm{VS}{ }^{-1}$ at $49 \% \mathrm{CH}_{4}$, and $0.14 \mathrm{~L}-\mathrm{CH}_{4}$ g-VS ${ }^{-1}$ at $69 \% \mathrm{CH}_{4}$, respectively [75, 80-82]. It was assumed that all recovered biogas would be burned in an on-site combined heat and power unit. In describing the baseline performance of the AD, it was assumed that $76 \%$ of the nitrogen is recovered which includes a $5 \%$ volatilization loss $[15,80]$. Phosphorus is assumed to be recovered with a 70\% efficiency for the baseline scenario [83]. For the optimistic and conservative cases, nitrogen and phosphorus recovery via AD were assumed to be $85 \%$ and $60 \%$, respectively $[15,80,83]$. 


\subsection{Alternative Process Scenarios}

Two alternative process scenarios were modeled and evaluated: a) the use of LEA as a co-

97 product and b) hydrothermal processing of the biomass to bio-oil through HTL. The LEA co-product

98 scenario provides further insight to claims made by previous TEAs in regard to the economic value of the LEA, and HTL represents a promising alternative processing technology due to the ability to process wet biomass and recover nutrients. For each of the LEA co-product and HTL scenarios, the baseline assumptions are used unless otherwise detailed.

\subsubsection{Lipid-extracted Algae (LEA) Co-product}

Analyses of the economics of biofuel production typically include discussion in regard to highervalued co-products derived from the LEA to improve the cost of biofuel production $[14,18]$. While the generation of revenue supplemental to that of biofuel through LEA co-products is economically advantageous, its implications on resource demand must be assessed. In this study an alternative scenario was modeled which considered using the LEA as a value added co-product. The LEA co-product scenario assumes all of the lipid-extracted biomass is removed from the process stream as a product after lipid extraction and used as aquaculture feed, and thus eliminating the AD system. It is assumed the minimal whole biomass recovered in the filtration of the centrate in the dewater step is added to the LEA product stream.

\subsubsection{Hydrothermal Liquefaction}

HTL is a technology currently being evaluated which breaks down biological matter into bio-oil and elemental components, providing the advantages of processing wet biomass and the partial conversion of proteins and carbohydrates to bio-oil [84-92]. The outputs of this process are bio-oil, biogas, nitrogen and potassium-rich aqueous phase, and precipitated phosphorus and sulfur [87, 93]. The modeled process replaces the extraction and the AD processes of the baseline production system. 
The bio-oil yield from the process is assumed to be $50 \%$ based on recovery of the $30 \%$ algal lipid

119 content and 20\% additional bio-oil through the conversion of carbohydrates and proteins [84-87, 93].

120 The percent phospholipid content was set to $0 \%$ because HTL strips the phosphates from any

121 phospholipids in the processing of the feedstock $[84,87]$. The biomass caught by the filter in the

122 dewater process is sent into the HTL process. Nutrient recovery was assumed to be $75 \%$ for nitrogen,

123 with the remaining nitrogen being contained in the bio-oil, and 95\% for precipitated phosphorus

124 recovery and processing [87].

Table 1. Summary of primary system parameter input values for the five microalgae to biofuel production scenarios modeled in this study with additional modeling parameters presented in the supplementary material.

\begin{tabular}{|c|c|c|c|c|c|}
\hline Parameter & Baseline & Optimistic & Conservative & LEA co-prod & HTL \\
\hline Process Loss (\%) & 1 & 0.5 & 2 & 1 & 1 \\
\hline C:N:P Ratio & $106: 16: 1$ & $166: 20: 1$ & 79:16:1 & $106: 16: 1$ & $106: 16: 1$ \\
\hline Hydrogen (\%) & 7.5 & 6 & 9 & 7.5 & 7.5 \\
\hline Lipid Content (\%) & 30 & 40 & 20 & 30 & 30 \\
\hline Phospholipids (\%) & 25 & 5 & 30 & 25 & 0 \\
\hline N Consumed by Microalgae (\%) & 99 & 100 & 98 & 99 & 99 \\
\hline Biomass Unharvested (\%) & 14.5 & 2.0 & 20.0 & 14.5 & 2.0 \\
\hline Biomass Unextracted (\%) & 10 & 5 & 15 & 10 & 0 \\
\hline Extracted Lipid Lost (\%) & 5 & 2 & 8 & 5 & 0 \\
\hline N Recovery (AD) (\%) & 76 & 85 & 60 & 0 & 66 \\
\hline P Recovery (AD) (\%) & 70 & 85 & 60 & 0 & 95 \\
\hline $\mathrm{CH}_{4}$ Production -Biomass $\left(\mathrm{L}-\mathrm{CH}_{4} \mathrm{~g}\right.$-VS $\left.{ }^{-1}\right)$ & 0.43 & 0.80 & 0.25 & $\mathrm{~N} / \mathrm{A}$ & $\mathrm{N} / \mathrm{A}$ \\
\hline $\mathrm{CH}_{4}$ Production - LEA $\left(\mathrm{L}-\mathrm{CH}_{4} \mathrm{~g}-\mathrm{VS}^{-1}\right)$ & 0.22 & 0.31 & 0.14 & $\mathrm{~N} / \mathrm{A}$ & $\mathrm{N} / \mathrm{A}$ \\
\hline $\mathrm{CH}_{4}$ in Biogas - Biomass (\%) & 67 & 62 & 72 & $\mathrm{~N} / \mathrm{A}$ & $\mathrm{N} / \mathrm{A}$ \\
\hline $\mathrm{CH}_{4}$ in Biogas - LEA (\%) & 59 & 49 & 69 & $\mathrm{~N} / \mathrm{A}$ & $\mathrm{N} / \mathrm{A}$ \\
\hline
\end{tabular}




\section{Results and Discussion}

\subsection{Total Resource Requirements}

Mass balance calculations were performed for the five biofuel production scenarios, each at the renewable fuel production level of $10 \mathrm{BGY}$, to quantify the required nitrogen and phosphorus demands. A fuel production level of $10 \mathrm{BGY}$ was selected based on a realistic contribution to the $2030 \mathrm{DOE}$ renewable fuel goal of $60 \mathrm{BGY}$ and represents a similar scale to other scalability assessments [32, 33]. Baseline results show for production of 10 BGY 167 million metric tonnes ( $\mathrm{Mmt}$ ) of biomass must be generated requiring 3.85 and $0.87 \mathrm{Mmt}$ of nitrogen and phosphorus respectively. Results for the other scenarios are normalized to the baseline results and presented in Figure 2 with a table of results presented in the supplementary material. Water consumption was also calculated based on the hydrogen content of the grown biomass and represents $<1 \%$ of total water demand compared to evaporation losses previously reported in the literature (details presented in the supplemental material) $[25,26]$.

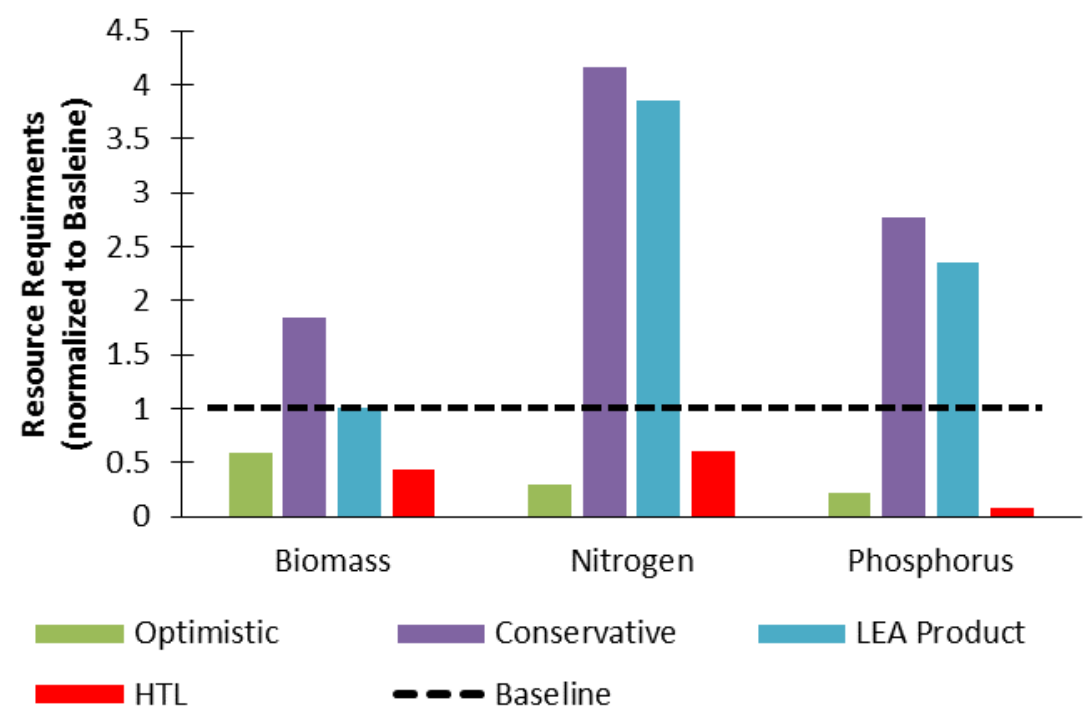

Figure 2. Biomass, nitrogen, and phosphorus requirements for the 4 alternative scenarios to produce 10 BGY of biofuel, normalized to the baseline requirements of $167 \mathrm{Mmt}$ biomass, $3.85 \mathrm{Mmt}$ nitrogen, and $0.87 \mathrm{Mmt}$ phosphorus. 
144 are illustrated through the optimistic and conservative results, with the baseline scenario portraying the expected resource demand from production that is realizable in the near-term. Over one hundred and fifty million metric tons of biomass will need to be grown in the baseline scenario to produce 10 BGY of

147 fuel corresponding to a land area of 3.5 million hectares based on the assumed growth rate of $13 \mathrm{~g} \mathrm{~m}^{-2}$

148 day $^{-1}$ [52]. This land requirement does not represent a resource constraint as concluded by previous

149 assessments $[26,27,94]$. The total nitrogen and phosphorus needs for the optimistic scenario are 150 approximately one-fourth those of the baseline scenario, with the conservative scenario requiring four 151 times the nitrogen and three times the phosphorus compared to the baseline scenario. The large 152 variation in nutrient demand can be attributed primarily to the range in efficiency of nutrient recovery in 153 the AD. The LEA co-product scenario, characterized as the baseline scenario without AD, has roughly the 154 same nutrient requirements as the conservative scenario. Alternatively, $\mathrm{HTL}$ has approximately half the 155 required biomass production and nitrogen demand from the baseline, and a phosphorus requirement 156 less than one-tenth of the baseline, similar to the optimistic scenario. The ratio of nitrogen input to 157 phosphorus input is much higher in the HTL scenario because of the high nitrogen content in the bio-oil, 158 an issue that necessitates further downstream processing [85]. The integration of HTL represents a 159 promising technology based on nutrient recovery.

\subsection{Scalability Assessment Based on Resource Availability} provided in the supplementary material. 


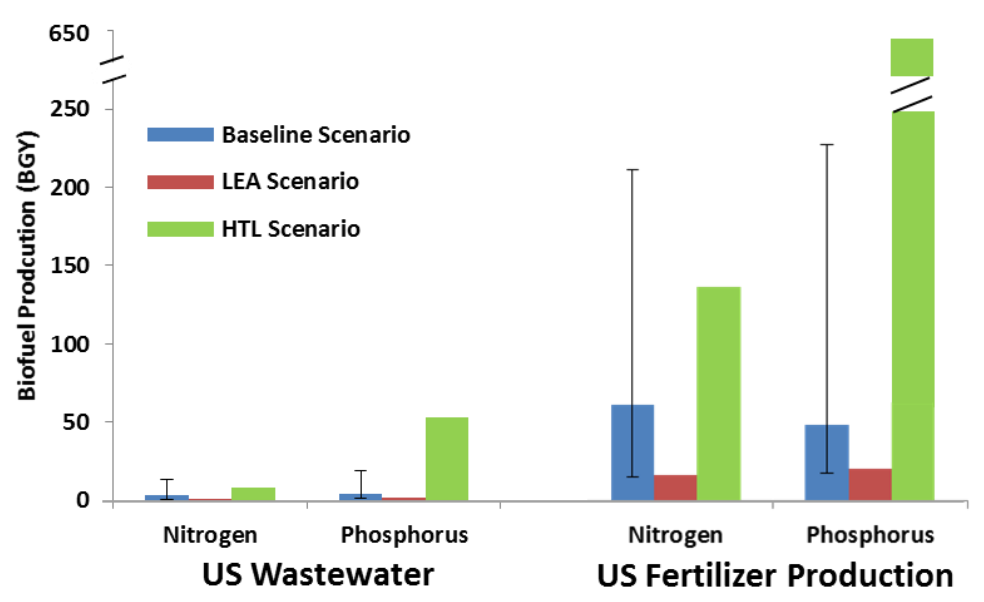

168 Figure 3. Scalability assessment: Biofuel productivity based on use of $100 \%$ of either US wastewater or fertilizer for the 169 modeled scenarios. Error bars on the baseline scenario are representative of the optimistic and conservative scenarios.

170 The scalability assessment shows nitrogen and phosphorous requirements are a potential

171 barrier to the scalability of microalgae biofuels. The nutrients available from wastewater correspond to

172 a fuel production level of $3.8 \mathrm{BGY}$ or $6 \%$ of the $2030 \mathrm{DOE}$ fuel goal for the baseline scenario with none of

173 the scenarios meeting the goal. Meeting a production level of $10 \mathrm{BGY}$ would require 2.6 times the

174 available wastewater in the US (based on the baseline scenario) illustrating wastewater to be a possible

175 supplement, but not the ultimate source for nitrogen or phosphorous. The HTL scenario is the most

176 promising with a production capacity of $14 \%$ of the 2030 DOE goal based on nitrogen availability.

178 significant strain on the US fertilizer market for the baseline scenario. The HTL and optimistic scenarios

179 represent promising pathways in terms of nutrient requirements. Meeting a production level of $10 \mathrm{BGY}$

180 would require $7.3 \%$ and $4.7 \%$ of the nitrogen fertilizer market and $1.6 \%$ and $4.3 \%$ of the phosphorus

181 market, based on the HTL and optimistic scenarios, respectively. However, the optimistic scenario

182 requires significant technological advancement from the current state while HTL has been demonstrated 183 at the pilot plant level [40]. 
Results from the LEA co-product scenario illustrate the necessity for the recycling of nutrients.

The nutrient requirements exceed the current resource and show that for significant levels of biofuel production, $>10 \mathrm{BGY}$, nutrients from the LEA must be recycled. The recycling requirement limits the end use as a value added product. Results from the scalability assessment show that independent of scenario, nutrient management represents an important aspect of microalgae scalability.

\subsection{Comparison to Previous Nutrient Assessments}

A variety of microalgae based TEA and LCA studies have reported nutrient requirements for the cultivation of microalgae but have failed to include nutrient availability at large-scale in the analysis [7-

$21,25,35,52]$. Incomplete resource assessments have led to a large uncertainty in the current requirements for large scale production [7-9, 15, 32-35, 52]. Results from previous studies were normalized to the baseline units of this study, 10 billion gallons of fuel production annually from 167 Mmt of biomass. Normalized nutrient demand values reported in surveyed literature range by a factor of 10 from 2.3 Mmt of nitrogen and $0.68 \mathrm{Mmt}$ of phosphorus $[15,52]$ to $24.5 \mathrm{Mmt}$ of nitrogen and 3.5 Mmt of phosphorus $[8,35]$ as shown in Figure 4.
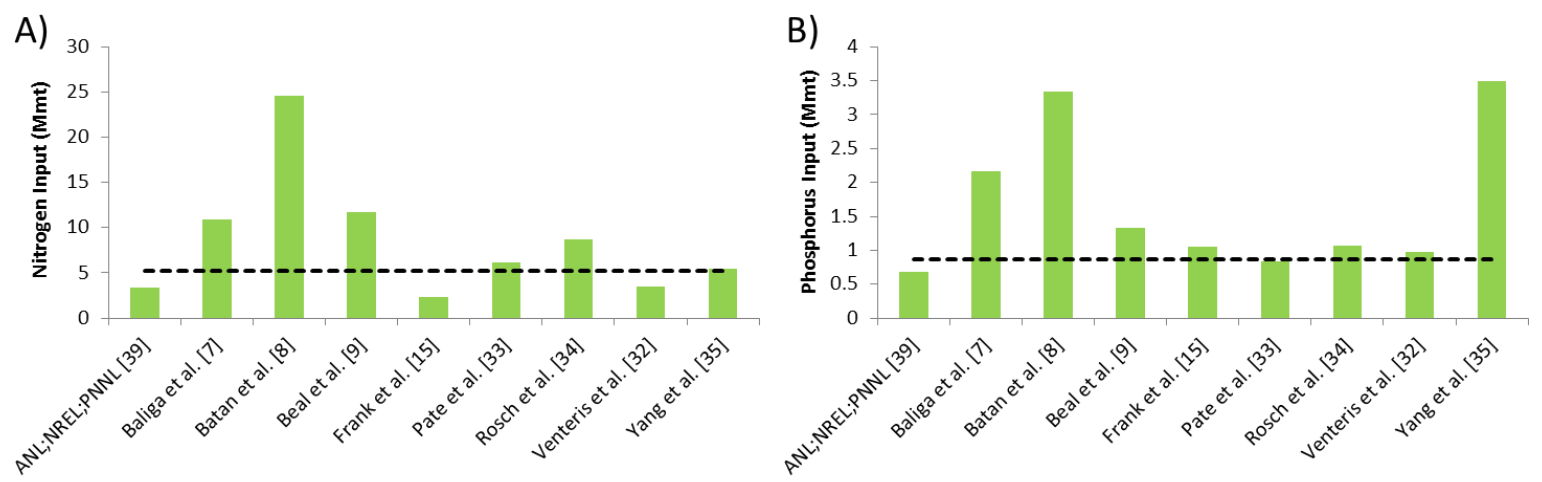

Figure 4. Results for (A) Nitrogen demand and (B) Phosphorus demand from various literature sources as compared to the baseline results of this study (black dotted line) at a fuel production level of $10 \mathrm{BGY}$.

The nutrient requirements in this study are 1.6 and 1.3 times the lowest values and 0.16 and 0.25 times the highest values reported in the literature surveyed for nitrogen and phosphorous requirements, respectively. Interestingly, when compared to the high productivity scenario from Pate et al. [33], the 
most comparable results to this study, the baseline requirements are $63 \%$ and $105 \%$ of their results for nitrogen and phosphorus. The differences and similarities in results occur through a combination of factors, specifically that Pate et al. [33] only consider the growth phase for nutrient requirements, neglect all losses, and assume high algal productivity, each of which introduces uncertainty.

208 Foundational assumptions in regard to nutrient availability also impact direct comparisons. Venteris et 209 al. [32] assume a nitrogen and phosphorous availability in wastewater that is 1.7 and 1.25 times higher than this study based on population and GIS assumptions. Compared to literature, the baseline results

211 obtained in this study are similar with results from previous studies, falling between the high and low

212 values reported. The large variance in previously reported results stem from differences in processing

213 pathways and engineering process model fidelity. Results from this study are derived from an improved

214 process model which describes a complete production system including recycling and system losses.

215 Transparency in the modeling work performed and the high level of detail enables a more holistic understanding of the nutrient requirements with the various scenarios used to bound the nutrient

217 requirements at scale.

\subsection{Sensitivity Analysis}

A sensitivity analysis was performed to illustrate which process parameters have the greatest

220 effect on resource demand and to ultimately guide future research. The sensitivity analysis was

221 performed by independently varying each system parameter by $\pm 20 \%$ from the baseline and recording

222 the nitrogen and phosphorus requirements and utilizing an analysis of variance to estimate t-ratios for

223 each input parameter. Results from the sensitivity to process parameters, in order of greatest impact on

224 resource requirements, are presented in Figure 5. Results were analyzed using a one tail distribution

225 with a 95\% confidence interval, resulting in a critical t-ratio of 2.1. The critical t-ratio provides the

226 boundary through which system parameters are deemed as sensitive or non-sensitive. The parameters

227 whose t-ratio magnitude is above the critical, and thus whose bar extends beyond the confidence 
229 ten parameters with the highest sensitivity based on t-ratio were included in Figure 5.

A)

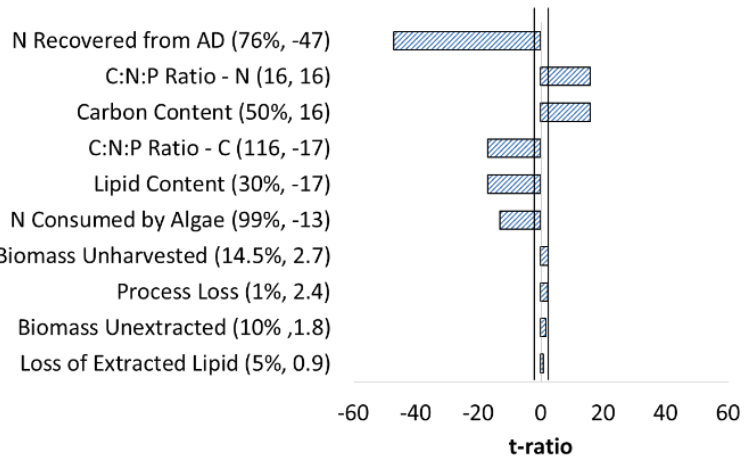

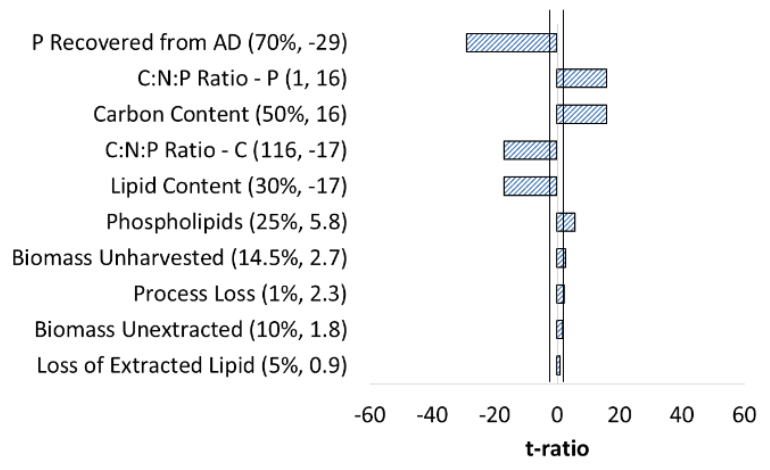

Figure 5. One-tailed results from sensitivity analysis of system parameters for (A) Nitrogen requirement and (B) Phosphorus requirement. Numbers in parenthesis correspond to baseline value followed by t-ratio; critical t-ratio equal to 2.1. Only the top 10 sensitive variables presented with additional results presented in supplementary material.

The two parameters whose variation has the greatest impact on system nutrient demand are the nitrogen and phosphorus recovery rates of the AD. It must be noted that AD technology has matured such that only minor increases in $\mathrm{N}$ and $\mathrm{P}$ recovery can be expected. However, advancement in nutrient recovery by use of an alternative technology such as $\mathrm{HTL}$, could dramatically impact the scalability. The next group of parameters most capable of driving down resource demand are those describing the composition of the microalgae strain. This demonstrates that the microalgae strain characteristics including $\mathrm{C}: \mathrm{N}: \mathrm{P}$ ratio, lipid content, phospholipid content, and carbon content must be thoroughly understood and even optimized through synthetic biology or other means for efficient nutrient use in microalgae growth and lipid production. Resource requirements for large-scale microalgae production can be reduced through technological improvements affecting these sensitive system parameters. 


\section{Conclusion}

A detailed and modular engineering system model was developed and used to determine total

247 system nutrient (nitrogen and phosphorus) requirements for five microalgae to biofuel production scenarios at a production level of $10 \mathrm{BGY}$, corresponding to a significant contribution toward the DOE

2492030 goal. Optimistic and conservative process scenarios were modeled in an effort to bound the 250 nutrient requirements for large-scale microalgae production with a baseline scenario intended to 251 represent a near-term commercial system. Baseline nutrient requirements for attaining the full DOE

2522030 goal dramatically exceed the nutrients available in wastewater and are equivalent to the current

253 fertilizer consumption in the US. Utilization of wastewater as the sole source of nutrients limits

254 microalgae biofuel production to 3.8 BGY based on the baseline scenario. The nutrient demand for 255 large-scale production requires nutrients to be recovered from the LEA, and thus LEA cannot be used as 256 an economically beneficial co-product. The HTL scenario shows that it has significant advantages over

257 the baseline scenario, including lower biomass production and nutrient requirements. Sensitivity 258 analysis shows that resource demand can be impacted through improvements in nutrient recycling and 259 microalgae strain characteristics. Results highlight the importance of nutrient management and the 260 limited impact integration with wastewater systems has on microalgae requirements at large-scale.

\section{Acknowledgements}

262 The authors gratefully acknowledge funding support from the Department of Energy, DE-EE0003114,

263 Utah Science and Technology Initiative for Economic Development, Utah State University, and Colorado 264 State University as well as support from Danna Quinn.

\section{Appendix A. Supplementary material}

266 Supplementary data associated with this article can be found in the online version. 


\section{References}

268 [1] Department of Energy. Alternative fuel transportation program; replacement fuel goal modification.

269 Office of Energy Efficiency and Renewable Energy. Department of Energy, 2007.

270 [2] J.K. Pittman, A.P. Dean, O. Osundeko. The potential of sustainable algal biofuel production using

271 wastewater resources. Bioresource Technology 102 (2011) 17-25.

272 [3] I. Woertz, A. Feffer, T. Lundquist, Y. Nelson. Algae grown on dairy and municipal wastewater for

273 simultaneous nutrient removal and lipid production for biofuel feedstock. Journal of Environmental

274 Engineering-Asce 135 (2009) 1115-22.

275 [4] N. Abdel-Raouf, A.A. Al-Homaidan, I.B.M. Ibraheem. Microalgae and wastewater treatment. Saudi J 276 Biol Sci 19 (2012).

277 [5] P.S. Lau, N.F.Y. Tam, Y.S. Wong. Wastewater nutrients ( $\mathrm{N}$ and $\mathrm{P}$ ) removal by carrageenan and alginate 278 immobilized Chlorella vulgaris. Environmental Technology 18 (1997) 945-51.

279 [6] M. Przytocka-Jusiak, M. Duszota, K. Matusiak, R. Mycielski. Intensive culture of Chlorella vulgaris/AA 280 as the second stage of biological purification of nitrogen industry wastewaters. Water Research 18 $281 \quad(1984) 1-7$.

282 [7] R. Baliga, S.E. Powers. Sustainable algae biodiesel production in cold climates. International Journal 283 of Chemical Engineering 4 (2010) 1-13.

284 [8] L. Batan, J. Quinn, B. Willson, T. Bradley. Net energy and greenhouse gas emission evaluation of 285 biodiesel derived from microalgae. Environmental Science and Technology 44 (2010) 7975-80.

286 [9] C.M. Beal, R.E. Hebner, M.E. Webber, R.S. Ruoff, A.F. Seibert. The energy return on investment for 287 algal biocrude: Results for a research production facility. BioEnergy Res 5 (2012) 341-62.

288 [10] L.B. Brentner, M.J. Eckelman, J.B. Zimmerman. Combinatorial life cycle assessment to inform 289 process design of industrial production of algal biodiesel. Environmental Science \& Technology 45 (2011) $290 \quad 7060-7$. 
291 [11] P.K. Campbell, T. Beer, D. Batten. Life cycle assessment of biodiesel production from microalgae in 292 ponds. Bioresource Technology 102 (2011) 50-6.

293 [12] A.F. Clarens, H. Nassau, E.P. Resurreccion, M.A. White, L.M. Colosi. Environmental impacts of algae294 derived biodiesel and bioelectricity for transportation. Environmental Science \& Technology 45 (2011) 295 7554-60.

296 [13] A.F. Clarens, E.P. Resurreccion, M.A. White, L.M. Colosi. Environmental life cycle comparison of 297 algae to other bioenergy feedstocks. Environmental Science \& Technology 44 (2010) 1813-9.

298 [14] R. Davis, A. Aden, P.T. Pienkos. Techno-economic analysis of autotrophic microalgae for fuel 299 production. Applied Energy 88 (2011) 3524-31.

300 [15] E.D. Frank, J. Han, I. Palou-Rivera, A. Elgowainy, M.Q. Wang. Life-cycle analysis of algal lipid fuels 301 with the GREET model. Center for Transportation Research, Energy Systems Division, Argonne National 302 Laboratory, Oak Ridge, TN, 2011.

303 [16] O. Jorquera, A. Kiperstok, E.A. Sales, M. Embirucu, M.L. Ghirardi. Comparative energy life-cycle 304 analyses of microalgal biomass production in open ponds and photobioreactors. Bioresource Technology $305101(2010)$ 1406-13.

306 [17] H.H. Khoo, P.N. Sharratt, P. Das, R.K. Balasubramanian, P.K. Naraharisetti, S. Shaik. Life cycle energy 307 and $\mathrm{CO} 2$ analysis of microalgae-to-biodiesel: Preliminary results and comparisons. Bioresource 308 Technology 102 (2011) 5800-7.

309 [18] T.J. Lundquist, I.C. Woertz, N.W.T. Quinn, J.R. Benemann. A realistic technology and engineering 310 assessment of algae biofuel production. Energy Biosciences Institute, Berkeley, CA, 2010.

311 [19] D. Luo, Z. Hu, D.G. Choi, V.M. Thomas, M.J. Realff, R.R. Chance. Life cycle energy and greenhouse 312 gas emissions for an ethanol production process based on blue-green algae. Environmental Science \& 313 Technology 44 (2011) 8670-7. 
314 [20] L.F. Razon, R.R. Tan. Net energy analysis of the production of biodiesel and biogas from the 315 microalgae: Haematococcus pluvialis and Nannochloropsis. Applied Energy 88 (2011) 3507-14.

316 [21] T. Shirvani, X. Yan, O.R. Inderwildi, P.P. Edwards, D.A. King. Life cycle energy and greenhouse gas

317 analysis for algae-derived biodiesel. Energy \& Environmental Science 4 (2011) 3773-8.

318 [22] V. Vasudevan, R.W. Stratton, M.N. Pearlson, G.R. Jersey, A.G. Beyene, J.C. Weissman, et al.

319 Environmental performance of algal biofuel technology options. Environ Sci Technol 46 (2012) 2451-9.

320 [23] D.L. Sills, V. Paramita, M.J. Franke, M.C. Johnson, T.M. Akabas, C.H. Greene, et al. Quantitative 321 uncertainty analysis of life cycle assessment for algal biofuel production. Environ Sci Technol 47 (2013) $322 \quad 687-94$.

323 [24] E. Menger-Krug, J. Niederste-Hollenberg, T. Hillenbrand, H. Hiessl. Integration of microalgae 324 systems at municipal wastewater treatment plants: Implications for energy and emission balances. 325 Environ Sci Technol 46 (2012) 11505-14.

326 [25] L. Batan, J.C. Quinn, T.H. Bradley. Analysis of water footprint of a photobioreactor microalgae 327 biofuel production system from blue, green and lifecycle perspectives. Algal Research 2 (2013) 196-203. 328 [26] M.S. Wigmosta, A.M. Coleman, R.J. Skaggs, M.H. Huesemann, L.J. Lane. National microalgae biofuel 329 production potential and resource demand. Water Resour Res 47 (2011) WOOH4.

330 [27] J. Quinn, K. Catton, N. Wagner, T. Bradley. Current large-scale US biofuel potential from microalgae 331 cultivated in photobioreactors. BioEnergy Res 5 (2012) 49-60.

332 [28] J.C. Quinn, K.B. Catton, S. Johnson, H.B. Thomas. Geographical assessment of microalgae biofuels 333 potential incorporating resource availability. BioEnergy Res 6 (2012) 591-600.

334 [29] E.R. Venteris, R.C. McBride, A.M. Coleman, R.L. Skaggs, M.S. Wigmosta. Siting algae cultivation 335 facilities for biofuel production in the United States: Trade-offs between growth rate, site 336 constructability, water availability, and infrastructure. Environ Sci Technol 48 (2014) 3559-66. 
[30] E.R. Venteris, R.L. Skaggs, A.M. Coleman, M.S. Wigmosta. An assessment of land availability and price in the coterminous United States for conversion to algal biofuel production. Biomass \& Bioenergy 47 (2012) 483-97.

[31] E.R. Venteris, R.L. Skaggs, A.M. Coleman, M.S. Wigmosta. A GIS cost model to assess the availability

341 of freshwater, seawater, and saline groundwater for algal biofuel production in the United States.

342 Environ Sci Technol 47 (2013) 4840-9.

343 [32] E.R. Venteris, R.L. Skaggs, M.S. Wigmosta, A.M. Coleman. A national-scale comparison of resource

344 and nutrient demands for algae-based biofuel production by lipid extraction and hydrothermal

345 liquefaction. Biomass \& Bioenergy 64 (2014) 276-90.

346 [33] R. Pate, G. Klise, B. Wu. Resource demand implications for US algae biofuels production scale-up.

$347 \quad$ Applied Energy 88 (2011) 3377-88.

348 [34] C. Rösch, J. Skarka, N. Wegerer. Materials flow modeling of nutrient recycling in biodiesel 349 production from microalgae. Bioresource Technology 107 (2012) 191-9.

350 [35] J. Yang, M. Xu, X. Zhang, Q. Hu, M. Sommerfeld, Y. Chen. Life-cycle analysis on biodiesel production

351 from microalgae: Water footprint and nutrients balance. Bioresource Technology 102 (2011) 159-65.

352 [36] L. Jiang, S. Luo, X. Fan, Z. Yang, R. Guo. Biomass and lipid production of marine microalgae using 353 municipal wastewater and high concentration of $\mathrm{CO}_{2}$. Applied Energy 88 (2011) 3336-41.

354 [37] P.J. McGinn, K.E. Dickinson, K.C. Park, C.G. Whitney, S.P. MacQuarrie, F.J. Black, et al. Assessment of 355 the bioenergy and bioremediation potentials of the microalga Scenedesmus sp. AMDD cultivated in 356 municipal wastewater effluent in batch and continuous mode. Algal Research 1 (2012) 155-65.

357 [38] E.B. Sydney, T.E. da Silva, A. Tokarski, A.C. Novak, J.C. de Carvalho, A.L. Woiciecohwski, et al. 358 Screening of microalgae with potential for biodiesel production and nutrient removal from treated 359 domestic sewage. Applied Energy 88 (2011) 3291-4. 
[39] R. Davis, C. Kinchin, J. Markham, E.C.D. Tan, L.M.L. Laurens. Process design and economics for the

361 conversion of algal biomass to biofuels: Algal biomass fractionation to lipid- and carbohydrate-derived

362 fuel products. U.S. Department of Energy Bioenergy Technologies Office2014.

363 [40] S. Jones, R. Davis, Y. Zhu, C. Kinchin, D. Anderson, R. Hallen, et al. Process design and economics for

364 the conversion of algal biomass to hydrocarbons: Whole algae hydrothermal liquefaction and upgrading.

365 U.S. Department of Energy Bioenergy Technologies Office2014.

366 [41] H. Passell, H. Dhaliwal, M. Reno, B. Wu, A. Ben Amotz, E. Ivry, et al. Algae biodiesel life cycle

367 assessment using current commercial data. J Environ Manag 129 (2013) 103-11.

368 [42] T. Shirvani, X.Y. Yan, O.R. Inderwildi, P.P. Edwards, D.A. King. Life cycle energy and greenhouse gas

369 analysis for algae-derived biodiesel. Energy \& Environmental Science 4 (2011) 3773-8.

370 [43] P. Azadi, G. Brownbridge, S. Mosbach, A. Smallbone, A. Bhave, O. Inderwildi, et al. The carbon

371 footprint and non-renewable energy demand of algae-derived biodiesel. Applied Energy 113 (2014)

$372 \quad 1632-44$.

373 [44] P. Collet, L. Lardon, A. Hélias, S. Bricout, I. Lombaert-Valot, B. Perrier, et al. Biodiesel from

374 microalgae - life cycle assessment and recommendations for potential improvements. Renewable

$375 \quad$ Energy $71(2014)$ 525-33.

376 [45] J.C. Quinn, T.G. Smith, C.M. Downes, C. Quinn. Microalgae to biofuels lifecycle assessment-multiple

377 pathway evaluation. Algal Research 4 (2014) 116-22.

378 [46] I.C. Woertz, J.R. Benemann, N. Du, S. Unnasch, D. Mendola, B.G. Mitchell, et al. Life cycle ghg

379 emissions from microalgal biodiesel - a ca-GREET model. Environ Sci Technol 48 (2014) 6060-8.

380 [47] V.O. Adesanya, E. Cadena, S.A. Scott, A.G. Smith. Life cycle assessment on microalgal biodiesel

381 production using a hybrid cultivation system. Bioresour Technol 163 (2014) 343-55. 

microalgal integrated biorefinery schemes: Empirical controlled growth studies and life cycle assessment. Bioresour Technol 151 (2014) 19-27.

[50] E. Crabbe, C. Nolasco-Hipolito, G. Kobayashi, K. Sonomoto, A. Ishizaki. Biodiesel production from

65-71.

[51] N.T. Dunford, M. Zhang. Pressurized solvent extraction of wheat germ oil. Food Research International 36 (2003) 905-9.

[52] ANL, NREL, PNNL. Renewable diesel from algal lipids: An integrated baseline for cost, emissions, and resource potential from a harmonized model. US Department of Energy Biomass Program. June 2012. [53] United States Department of Energy. Office of Energy Efficiency and Renewable Energy. National alliance for advanced biofuels and bioproducts (NAABB) final report. 2014. [54] J.C. Quinn, T. Yates, N. Douglas, K. Weyer, J. Butler, T.H. Bradley, et al. Nannochloropsis production metrics in a scalable outdoor photobioreactor for commercial applications. Bioresource Technology 117 (2012) 164-71.

[55] C. Adams, V. Godfrey, B. Wahlen, L. Seefeldt, B. Bugbee. Understanding precision nitrogen stress to 400 optimize the growth and lipid content tradeoff in oleaginous green microalgae. Bioresource Technology $131(2013)$ 188-94.

402 [56] L. Chen, T. Liu, W. Zhang, X. Chen, J. Wang. Biodiesel production from algae oil high in free fatty 403 acids by two-step catalytic conversion. Bioresource Technology 111 (2012) 208-14.

404 [57] H. Chaoui, S.R. Eckhoff. Biomass feedstock storage for quantity and quality preservation. 405 Engineering and science of biomass feedstock production and provision, Springer2014. p. 165-93. 
[58] E. Montaini, G. Chini Zittelli, M. Tredici, E. Molina Grima, J. Fernandez Sevilla, J. Sanchez Perez.

407 Long-term preservation of $<\mathrm{i}>$ tetraselmis suecica</i>: Influence of storage on viability and fatty acid 408 profile. Aquaculture 134 (1995) 81-90.

409 [59] H. Rodger Harvey, J.H. Tuttle, J. Tyler Bell. Kinetics of phytoplankton decay during simulated

410 sedimentation: Changes in biochemical composition and microbial activity under oxic and anoxic

411 conditions. Geochimica et Cosmochimica Acta 59 (1995) 3367-77.

412 [60] Y. Chisti. Biodiesel from microalgae. Biotechnology Advances 25 (2007) 294-306.

413 [61] A.S. Mirón, M.C.C. García, A.C. Gómez, F.G.a. Camacho, E.M. Grima, Y. Chisti. Shear stress tolerance 414 and biochemical characterization of Phaeodactylum tricornutum in quasi steady-state continuous 415 culture in outdoor photobioreactors. Biochemical Engineering Journal 16 (2003) 287-97.

416 [62] J.L. Zelibor Jr., L. Romankiw, P.G. Hatcher, R.R. Colwell. Comparative analysis of the chemical 417 composition of mixed and pure cultures of green algae and their decomposed residues by c nuclear 418 magnetic resonance spectroscopy. Appl Environ Microbiol 54 (1988) 1051-60.

419 [63] M.Y. Roleda, S.P. Slocombe, R.J.G. Leakey, J.G. Day, E.M. Bell, M.S. Stanley. Effects of temperature 420 and nutrient regimes on biomass and lipid production by six oleaginous microalgae in batch culture 421 employing a two-phase cultivation strategy. Bioresource Technology 129 (2013) 439-49.

422 [64] A.C. Redfield. The biological control of chemical factors in the environment. American Scientist 46 $423 \quad$ (1958) 205-21.

424 [65] J.C. Quinn, C.W. Turner, T.H. Bradley. Scale-up of flat plate photobioreactor considering diffuse and 425 direct light characteristics. Biotechnology and Bioengineering 109 (2011) 363-70.

426 [66] V. Smith. Calculating the nutrient requirements of algal biomass production. Algal Biomass Summit. 427 Algal Biomass Organization, Denver, CO, 2012.

428 [67] K. Fagerstone, J. Quinn, T. Bradley, S. DeLong, A. Marchese. Quantification of direct nitrous oxide 429 emissions from microalgae cultivation. Environmental Science \& Technology 45 (2011) 9449-56. 
[68] S. Ferrón, D.T. Ho, Z.I. Johnson, M.E. Huntley. Air-water fluxes of N2O and CH4 during microalgae

431 (Staurosira sp.) cultivation in an open raceway pond. Environmental Science \& Technology 46 (2012)

$432 \quad 10842-8$.

433 [69] M.Y. Roleda, S.P. Slocombe, R.J.G. Leakey, J.G. Day, E.M. Bell, M.S. Stanley. Effects of temperature

434 and nutrient regimes on biomass and lipid production by six oleaginous microalgae in batch culture

435 employing a two-phase cultivation strategy. Bioresource Technology 129 (2013) 439-49.

436 [70] R.W. Harris, M.J. Cullinane Jr, P.T. Sun. Process design and cost estimating algorithms for the

437 computer assisted procedure for design and evaluation of wastewater treatment systems (capdet). DTIC

438 Document1982.

439 [71] T.-S. Sim, A. Goh, E. Becker. Comparison of centrifugation, dissolved air flotation and drum filtration

440 techniques for harvesting sewage-grown algae. Biomass 16 (1988) 51-62.

441 [72] N. Uduman, Y. Qi, M.K. Danquah, G.M. Forde, A. Hoadley. Dewatering of microalgal cultures: A

442 major bottleneck to algae-based fuels. Journal of Renewable and Sustainable Energy 2 (2010) 012701.

443 [73] V. Yanovsky. Westfalia separator food tec. In: V. Yanovsky, (Ed.). GEA, Oelde, Germany, 2009.

444 [74] J. Sheehan, T. Dunahay, J. Benemann, P. Roessler. A look back at the US department of energy's

445 aquatic species program: Biodiesel from algae. NREL report (1998) TP-580-24190.

446 [75] E.A. Ehimen, Z.F. Sun, C.G. Carrington, E.J. Birch, J.J. Eaton-Rye. Anaerobic digestion of microalgae

447 residues resulting from the biodiesel production process. Applied Energy 88 (2011) 3454-63.

448 [76] D.J. Chmielewski, V. Manousiouthakis, B. Tilton, B. Felix. Loss accounting and estimation of leaks

449 and instrument biases using time-series data. Industrial \& engineering chemistry research 39 (2000)

$450 \quad 2336-44$.

451 [77] J. Pinto, M. Joly, L. Moro. Planning and scheduling models for refinery operations. Computers \&

452 Chemical Engineering 24 (2000) 2259-76. 
[78] M. Ras, L. Lardon, S. Bruno, N. Bernet, J.-P. Steyer. Experimental study on a coupled process of

454 production and anaerobic digestion of Chlorella vulgaris. Bioresource Technology 102 (2011) 200-6.

455 [79] B. Sialve, N. Bernet, O. Bernard. Anaerobic digestion of microalgae as a necessary step to make

456 microalgal biodiesel sustainable. Biotechnology Advances 27 (2009) 409-16.

457 [80] R.D. Eric Jarvis, Craig Frear. Efficient use of algal biomass residues for biopower production with

458 nutrient recycle: Final project report. In: N.R.E. Laboratory, (Ed.). National Renewable Energy

459 Laboratory2013.

460 [81] R. Samson, A. Leduy. Biogas production from anaerobic digestion of Spirulina maxima algal biomass.

461 Biotechnology and Bioengineering 24 (1982) 1919-24.

462 [82] H.-W. Yen, D.E. Brune. Anaerobic co-digestion of algal sludge and waste paper to produce methane.

463 Bioresource Technology 98 (2007) 130-4.

464 [83] J.A. Field, R.B. Reneau Jr, W. Kroontje, J.S. Caldwell. Nutrient recoveries from plug-flow anaerobic

465 digestion of poultry manure. Agricultural Wastes 13 (1985) 207-16.

466 [84] P. Biller, A.B. Ross. Potential yields and properties of oil from the hydrothermal liquefaction of

467 microalgae with different biochemical content. Bioresource Technology 102 (2011) 215-25.

468 [85] Z. Shuping, W. Yulong, Y. Mingde, I. Kaleem, L. Chun, J. Tong. Production and characterization of

469 bio-oil from hydrothermal liquefaction of microalgae Dunaliella tertiolecta cake. Energy 35 (2010) 5406-

47011.

471 [86] S.S. Toor, L. Rosendahl, A. Rudolf. Hydrothermal liquefaction of biomass: A review of subcritical

472 water technologies. Energy 36 (2011) 2328-42.

473 [87] M. Biddy, R. Davis, S. Jones, Y. Zhu. Whole algae hydrothermal liquefaction technology pathway.

474 Technical Report (2013).

475 [88] U. Jena, K.C. Das, J.R. Kastner. Effect of operating conditions of thermochemical liquefaction on 476 biocrude production from Spirulina platensis. Bioresour Technol 102 (2011) 6221-9. 
477 [89] P.J. Valdez, J.G. Dickinson, P.E. Savage. Characterization of product fractions from hydrothermal

478 liquefaction of Nannochloropsis sp. And the influence of solvents. Energy and Fuels 25 (2011) 3235-43.

479 [90] D.R. Vardon, B.K. Sharma, J. Scott, G. Yu, Z. Wang, L. Schideman, et al. Chemical properties of

480 biocrude oil from the hydrothermal liquefaction of Spirulina algae, swine manure, and digested

481 anaerobic sludge. Bioresour Technol 102 (2011) 8295-303.

482 [91] G. Yu, Y. Zhang, L. Schideman, T.L. Funk, Z. Wang. Hydrothermal liquefaction of low lipid content 483 microalgae into bio-crude oil. Transactions of the ASABE 54 (2011) 239-46.

484 [92] L. Garcia Alba, C. Torri, C. Samorì, J. Van Der Spek, D. Fabbri, S.R.A. Kersten, et al. Hydrothermal 485 treatment (HTT) of microalgae: Evaluation of the process as conversion method in an algae biorefinery 486 concept. Energy and Fuels 26 (2012) 642-57.

487 [93] D.C. Elliott, T.R. Hart, A.J. Schmidt, G.G. Neuenschwander, L.J. Rotness, M.V. Olarte, et al. Process 488 development for hydrothermal liquefaction of algae feedstocks in a continuous-flow reactor. Algal $489 \quad$ Research 2 (2013) 445-54.

490 [94] J.W. Moody, C.M. McGinty, J.C. Quinn. Global evaluation of biofuel potential from microalgae.

491 Proceedings of the National Academy of Sciences (2014).

492 [95] G. Tchobanoglous, F.L. Burton, H. Stensel. Wastewater engineering treatment, disposal, and reuse. 493 New York, McGraw-Hill, 1991.

494 [96] Environmental Protection Agency. Introduction to the national pretreatment program. Office of 495 Wastewater Management. 2011.

496 [97] United States Geological Survey. Minerals yearbook 2011. 